\title{
Absorbable Plate as a Perpendicular Strut for Acute Saddle Nose Deformities
}

\author{
Jong Gyu Kim ${ }^{1}$, Seung Chul Rhee ${ }^{1}$, Pil Dong $\mathrm{Cho}^{1}$, Deok Jung Kim ${ }^{2}$, Soo Hyang Lee ${ }^{1}$ \\ ${ }^{1}$ Department of Plastic and Reconstructive Surgery, Ilsan Paik Hospital, Inje University College of Medicine, Goyang; \\ ${ }^{2}$ Topclass Plastic Surgery, Seoul, Korea
}

Background Nasal pyramid fractures accompanied by saddle nose deformities are not easily corrected by closed reduction. We used an absorbable plate as a perpendicular strut to support the collapsed "keystone area" and obtained good results.

Methods Between September 2008 and June 2011, 18 patients who had nasal pyramid fractures with saddle nose deformities underwent surgery. Pre- and postoperative facial computed tomographic images and photographs were taken to estimate outcomes. The operative technique included the mucoperichondrial dissection of the nasal septum, insertion of an absorbable plate prepared to an appropriate length to support the "keystone area", and fixation of the absorbable plate strut to the cartilaginous septum.

Results Functional and esthetic outcomes were satisfactory in all patients. Eleven patients assessed the postoperative appearance of the external nose as 'markedly improved' and 7 patients as 'improved'. The 5 surgeons scored the results as a mean of 4.5 on a 5 -point scale. Conclusions The use of an absorbable plate as a perpendicular strut requires no additional procedures because the plate is gradually absorbed. The mechanical strength provided by a buttress between the "keystone area" and the maxillary crest lasts for a long time before the strut is absorbed.

Keywords Absorbable implants / Nasal bone / Fractures, closed
Correspondence: Soo Hyang Lee Department of Plastic and Reconstructive Surgery, Ilsan Paik Hospital, Inje University College of Medicine, 170 Juhwa-ro, Ilsanseo-gu, Goyang 411-706, Korea Tel: +82-31-910-7320 Fax: +82-31-910-7814 E-mail: shyanglee@naver.com
Presented at the 66th Congress of the Korean Society of Plastic and Reconstructive Surgeons, May 7-9, 2009.

No potential conflict of interest relevant to this article was reported.

Received: 10 Jan 2012 • Revised: 20 Feb 2012 • Accepted: 20 Feb 2012

pISSN: 2234-6163 • elSSN: 2234-6171 • http://dx.doi.org/10.5999/aps.2012.39.2.113• Arch Plast Surg 2012;39:113-117

\section{INTRODUCTION}

Nasal pyramid fractures most commonly occur in the facial skeleton and are usually treated by closed reduction. Although nasal fractures are considered minor injuries, they have a high incidence of posttraumatic nasal deformities (14\% to $50 \%)$ [1]. In particular, traumatic collapse of the "keystone area" is likely to cause saddle nose deformities, which are not easily corrected by closed reduction or conventional septal surgery. In this study, we employed absorbable plates to support the "keystone area" in an attempt to improve the instability of a fractured septum under the "keystone area" and to minimize saddle nose deformities. The use of the absorbable plate as a strut led to optimal aesthetic and functional results.

\section{METHODS}

Between September 2008 and June 2011, a total of 18 patients who had posttraumatic saddle nose deformities that were not corrected by closed reduction underwent a concomitant sup- 
plementary procedure. The mean age of the patients was 34.2 years (range, 15 to 58 years). Seventeen patients were male and one patient was female. Two of the male patients had a previous history of submucous resection of the septal cartilage. One patient had a concurrent unilateral blowout fracture of the medial orbital wall (Table 1).

Correction of nasal and septal fractures was attempted via the closed approach. Because the reduced nasal bone and septum were not maintained in their proper position and fell inwards, we made a hemitransfixion incision followed by meticulous submucoperichondrial dissection without tearing the septal mucosa. After we identified the septal fracture site, a 2.0-mm-thick, 6-hole, $1.2 \times 5.5 \times 37 \mathrm{~mm}$ absorbable plate made of polylactic acid copolymer (Biosorb, Linvatec, Tempere, Finland) was prepared at an appropriate length to support the "keystone area" (Fig. 1). Then, the depressed area was corrected and supported by insertion of the absorbable plate strut between the nasal dorsum and the maxillary crest at the concave side of the fractured septum (Figs. 2, 3). The absorbable plate strut was fixed to the cartilaginous septum with 5-0 vicryl mattress sutures (Fig. 3). Each nose was packed with Merocel and protected with a thermoplastic external nasal splint. The nasal packs were removed 3 days after surgery. Open reduction of blowout fracture was performed first in the patient with the blowout fracture.

Facial computed tomographic scans were taken to assess preoperative and postoperative bony alignments (Fig. 4). The mean follow-up duration was 8 months (range, 4 to 11 months). Each patient assessed the postoperative appearance of the external nose as 'not improved, 'improved' or 'markedly improved. Five surgeons scored the results on a 5-point scale by photographic assessment.

\section{Table 1. Information of patients}

\begin{tabular}{|c|c|c|c|c|c|c|}
\hline Case & Age/Sex & Trauma & $\begin{array}{l}\text { Follow-up } \\
\text { (mo) }\end{array}$ & Complication & $\begin{array}{c}\text { Patient's } \\
\text { assessment } \\
(\mathrm{NI}, \mathrm{I}, \mathrm{MI})\end{array}$ & $\begin{array}{c}\text { Doctor's } \\
\text { assessment } \\
(0-5)\end{array}$ \\
\hline 1 & $20 / M$ & Sports injury & 11 & None & $\mathrm{Ml}$ & 5 \\
\hline 2 & $33 / \mathrm{M}$ & Slip down/septoplasty by SMR & 10 & None & $\mathrm{Ml}$ & 5 \\
\hline 3 & $16 / M$ & Motorcycle crash & 10 & None & I & 4 \\
\hline 4 & $22 / M$ & Assault injury/concomitant with BOF & 9 & None & $\mathrm{Ml}$ & 4 \\
\hline 5 & $54 / \mathrm{M}$ & Slip down & 9 & None & $\mathrm{Ml}$ & 5 \\
\hline 6 & $33 / \mathrm{M}$ & Slip down & 8 & None & Ml & 5 \\
\hline 7 & $21 / F$ & Fall down & 8 & None & $\mathrm{Ml}$ & 5 \\
\hline 8 & $52 / \mathrm{M}$ & Vehicle crash & 5 & None & 1 & 4 \\
\hline 9 & $27 / M$ & Sports injury/septoplasty by SMR & 4 & None & I & 5 \\
\hline 10 & $25 / M$ & Assault injury & 10 & None & Ml & 5 \\
\hline 11 & $58 / \mathrm{M}$ & Vehicle crash & 9 & None & I & 4 \\
\hline 12 & $15 / M$ & Sports injury & 9 & None & $\mathrm{Ml}$ & 4 \\
\hline 13 & $58 / \mathrm{M}$ & Sports injury & 7 & None & $\mathrm{Ml}$ & 5 \\
\hline 14 & $39 / \mathrm{M}$ & Assault injury & 9 & None & 1 & 3 \\
\hline 15 & $42 / \mathrm{M}$ & Assault injury & 8 & None & $\mathrm{Ml}$ & 5 \\
\hline 16 & $37 / M$ & Slip down & 7 & None & I & 5 \\
\hline 17 & $42 / \mathrm{M}$ & Vehicle crash & 6 & None & I & 4 \\
\hline 18 & $22 / M$ & Assault injury & 5 & None & $\mathrm{Ml}$ & 5 \\
\hline
\end{tabular}

\section{Fig. 1. Trimming of an absorbable plate}

(A) A 2.0-mm-thick, 6-hole, $1.2 \times 5.5 \times 37 \mathrm{~mm}$ bioabsorbable plate made of polylactic acid copolymer. (B) One hole was trimmed to fit the distance between the "keystone area" and the maxillary crest.
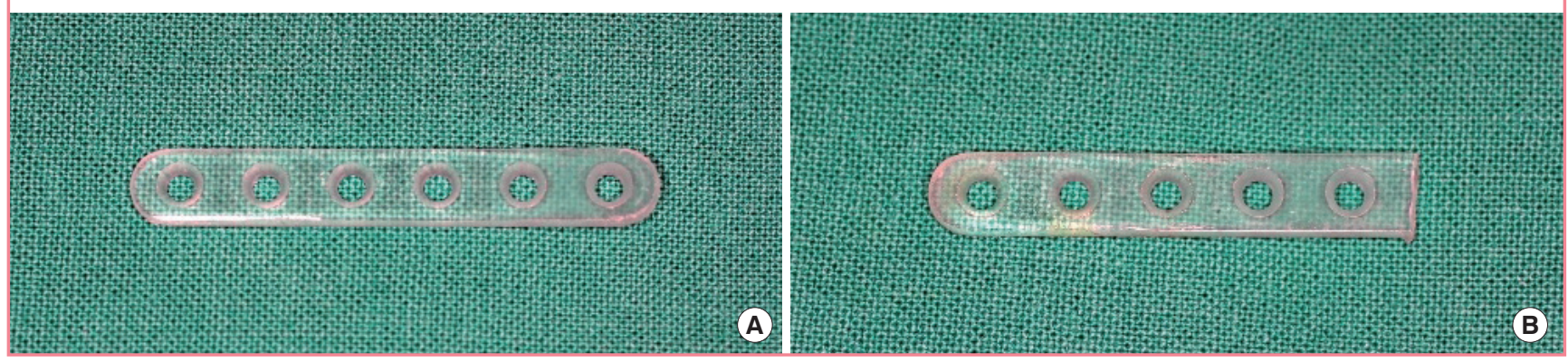
Fig. 2. Schematic and CT images of an absorbable plate strut

(A) Schematic view of an absorbable plate strut inserted to support the unstable nasal pyramid after reduction. (B) Postoperative CT scan demonstrating that the plate is positioned perpendicular to the nasal dorsum for stronger bearing force against the "keystone area".
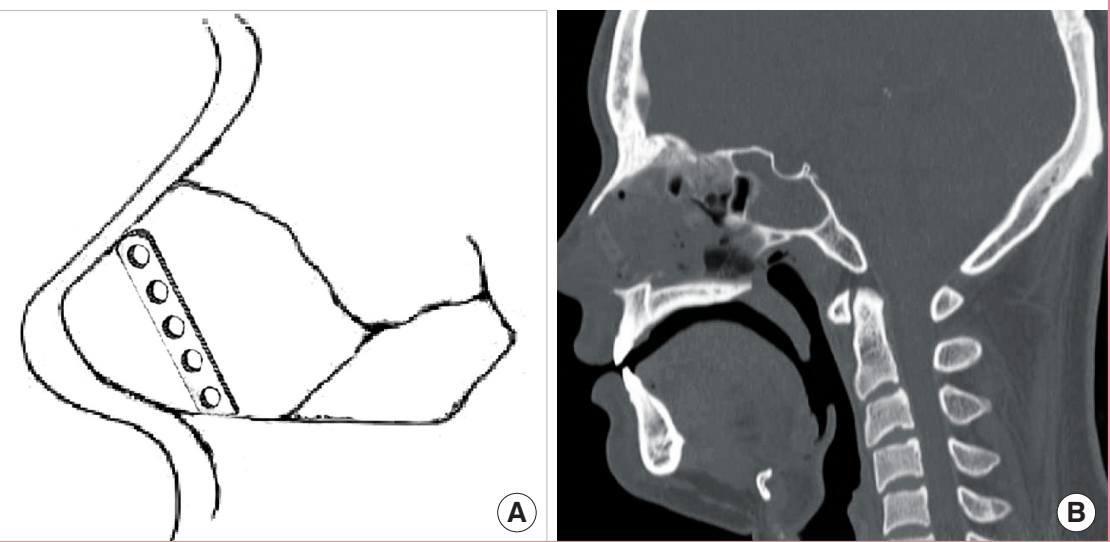

\section{Fig. 3. Intraoperative endoscopic views of the septal cartilage}

(A) A black arrow indicates the septal fracture site. A fractured and displaced septal cartilage is seen after wide mucoperichondrial dissection. (B) A black arrow indicates the septal fracture site. The injured cartilaginous septum was manually reduced. (C) An absorbable plate strut is placed beside the reduced septal cartilage.
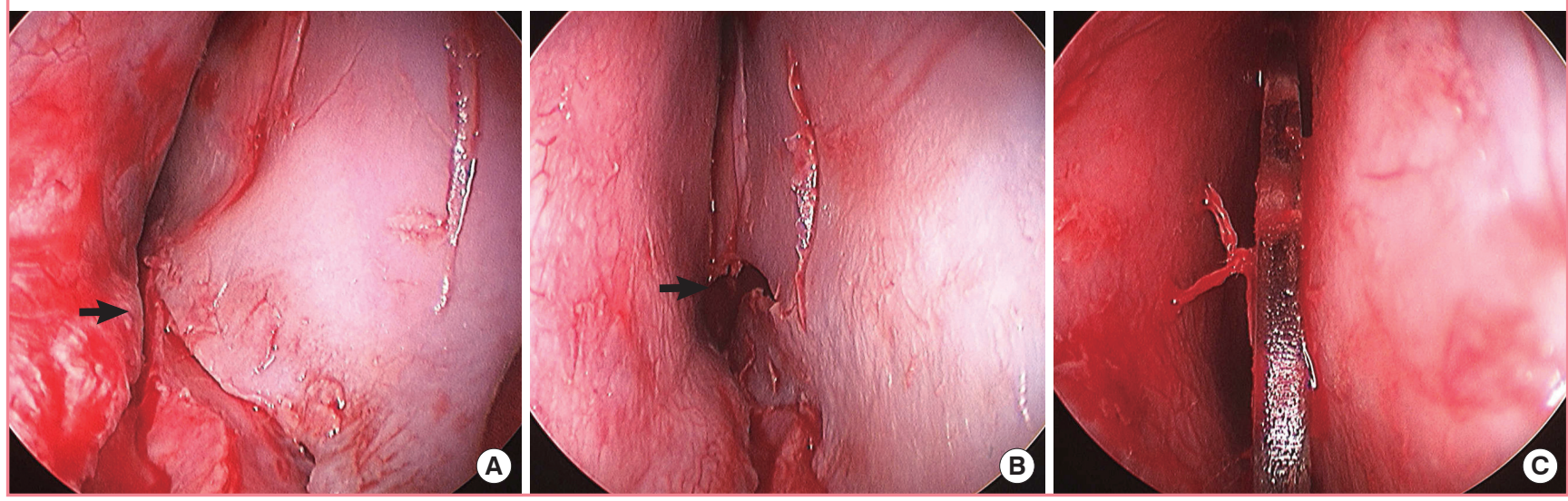

\section{Fig. 4. Facial bone CT images}

(A) Preoperative facial bone CT after trauma. (B) CT scan taken 7 months after surgery.

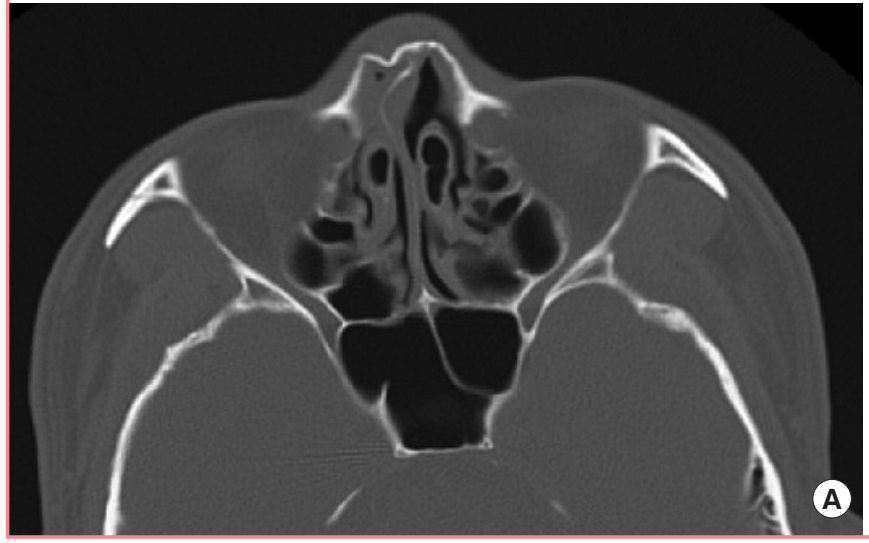

\section{RESULTS}

Six patients had significant deformities of the nasal septum. Two

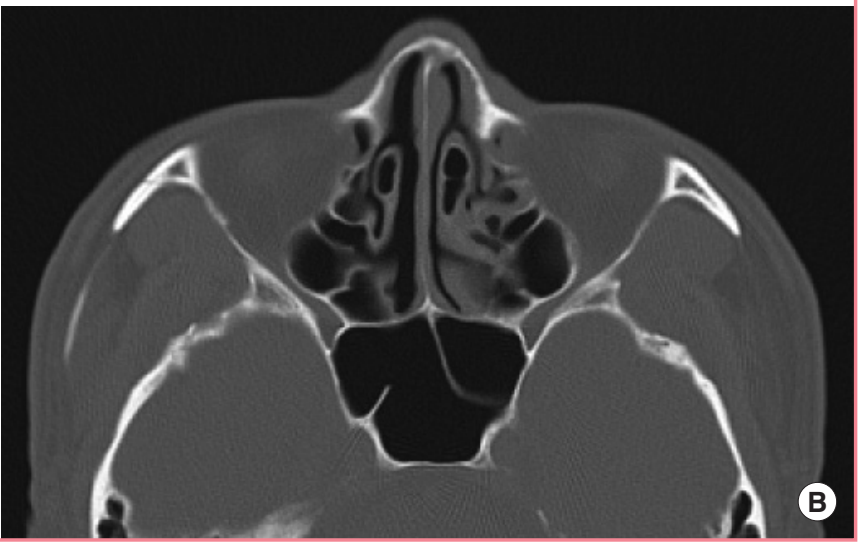

patients had severe saddle nose deformities as compared to nasal fractures because they had undergone a submucous resection earlier. 
The mean operation time was 39 minutes. Functional and esthetic outcomes were satisfactory in all patients. Eleven patients assessed the postoperative appearance of the external nose as 'markedly improved' and 7 patients as 'improved. The 5 surgeons scored the results as a mean of 4.5 points (range, 3 to 5 points) (Table 1 ). Surgical correction of traumatic saddle nose deformity using an absorbable plate strut resulted in good nasal projection and symmetry as well as continuous stability of the "keystone area" without serious complications during the follow-up period (Figs. 5, 6).

\section{DISCUSSION}

Bony pyramid fractures with minor septal injuries are generally treated with closed reduction, bilateral intranasal placement of silastic splints, and nasal packing. This treatment method is sufficient for satisfactory outcomes in the majority of cases. However,

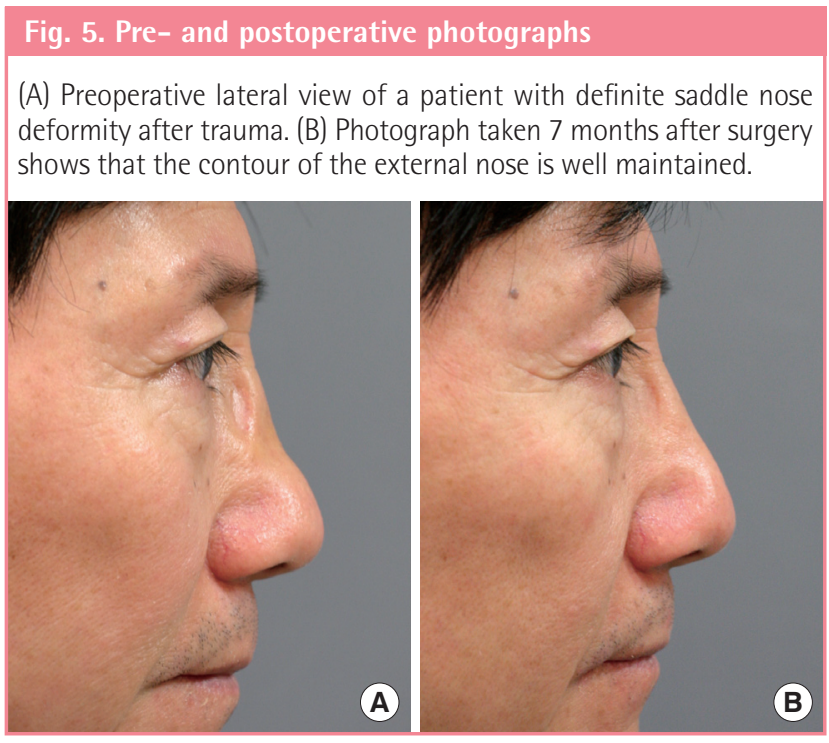

if unstable nasal fractures with significant septal injuries occur, the aforementioned method cannot ensure accurate correction. Even though temporary correction of immediate deformities is feasible through closed reduction, it is difficult to maintain the immediate postoperative state until the fractured nasal pyramid is completely healed. In such cases, more invasive methods are required to obtain desirable results $[2,3]$.

There have been many studies of the appropriate support for unstable fracture of the nasal bone and septum. Yabe and $\mathrm{Mu}-$ raoka [4] fixed the septal cartilage to the frontal process of the maxillary bone with a K-wire. However, they pointed out that the method is not indicated in patients with an unstable frontal process. Autologous tissues, such as conchal and costal cartilages, can be used to correct traumatic saddle nose deformities [5]. However, this technique may lead to donor site morbidities and take much time to perform. Moreover, it is not easy to har-

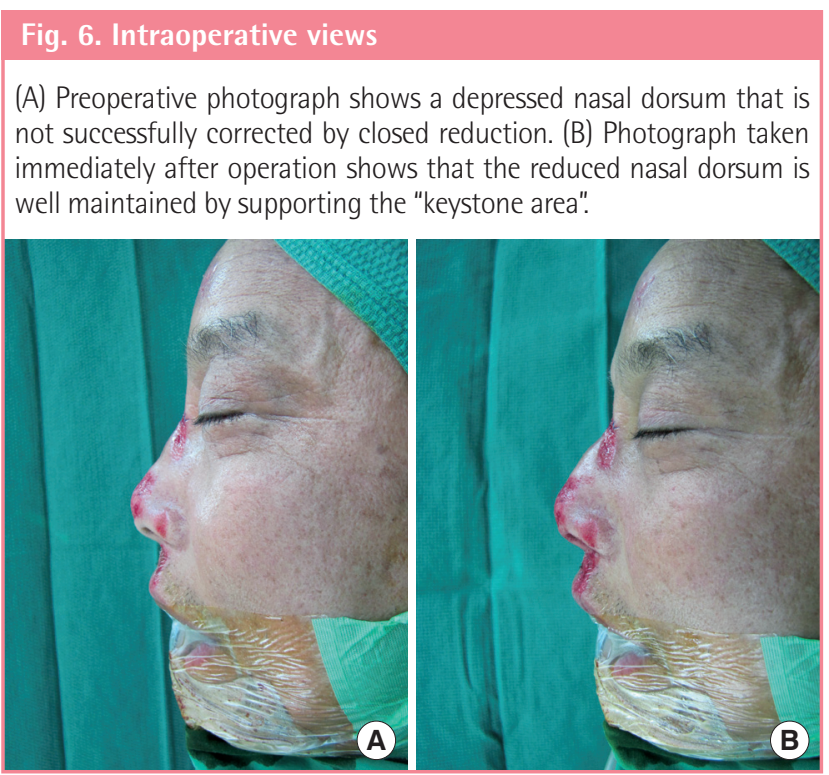

Fig. 7. Pre- and postoperative facial bone CT images

(A) Preoperative CT scan demonstrating collapse of the "keystone area." (B) Immediate postoperative view of an absorbable plate supporting the fractured nasal dorsum.
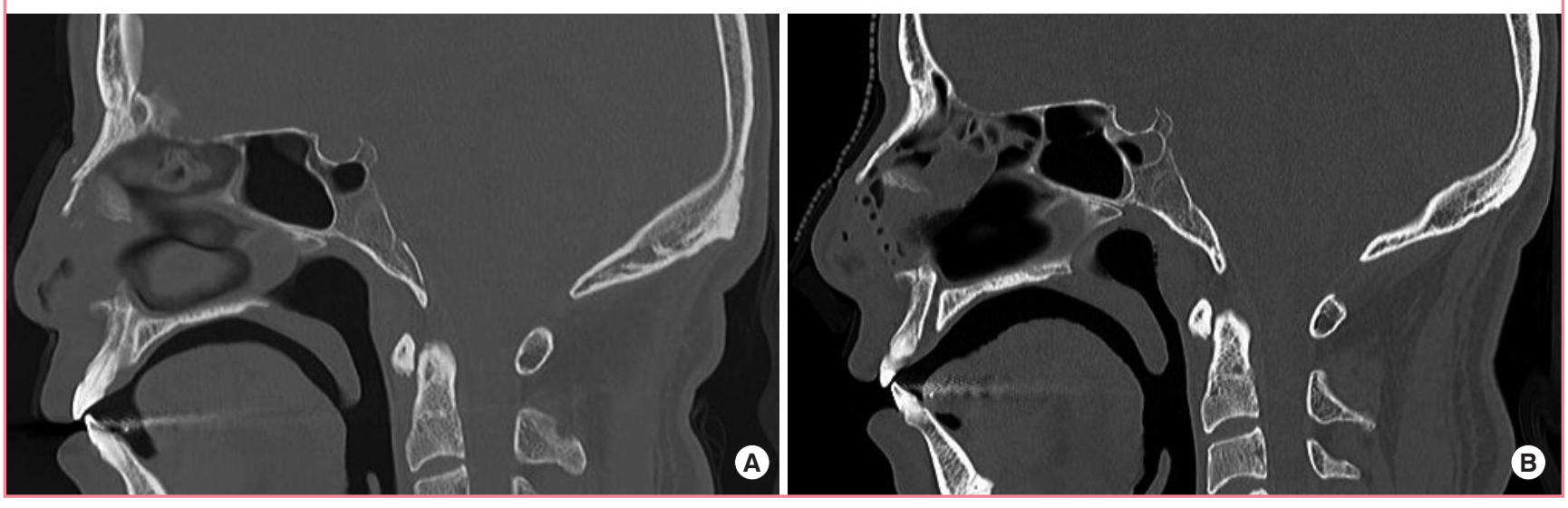
vest sufficient quantities of straight cartilage. Many studies have proposed various methods of using synthetic materials, such as molded Surgicel [6], absorbable bone pin (Neofix pin, Gunze, Osaka, Japan) [7], polydioxanone foil (PDS, Ethicon, Norderstedt, Germany) [8], and absorbable polymer membrane (PolyMax, Synthes, Oberdorf, Switzerland) [9], which are biomechanically similar to the septal cartilage and require about 7 months to be absorbed.

We attempted to make a direct strut for the "keystone area" using an absorbable plate in order to support the unstable nasal pyramid after reduction. The present study demonstrated the reliability and safety of the bioabsorbable plate. It is thought that the absorbable plate had strength enough to support the unstable "keystone area" while this area healed completely.

Our procedure was restricted to patients with immediate saddle nose deformities. The patients were left with a relatively intact mucoperichondrium, especially after dissection, so as not to expose the implanted absorbable plates. Meticulous dissection of the mucoperichondrium was performed on both sides of the septum. Since the commercially available 6-hole absorbable plate was too long, we cut one hole off the plate to fit the distance from the "keystone area" to the maxillary crest.

For stronger bearing force against the bony pyramid, the strut was inserted perpendicular to the nasal dorsum (Fig. 7). The authors present cases in which saddle nose deformities resulted due to trauma of the "keystone area" and place emphasis on the allocation of the strut between the "keystone area" and the maxillary crest. However, placement of the strut could be modified to provide anatomic support for instability in any part of the nasal pyramid. The well prepared strut was stable between the nasal bone and the maxilla, but vicryl sutures were applied to completely fix the plate to the septum. This step straightens the deformed cartilage septum.

Immediate saddle nose deformities caused by concurrent traumas frequently occur in patients who have a history of submucous resection. Our technique can bring a solution to this problem. The absorbable plate as an artificial strut is an excellent substitute for autologous tissue and can provide enough strength to maintain the proper shape of the nasal dorsum during the healing period.

In conclusion, to correct immediate traumatic saddle nose deformities, an absorbable plate strut is a good choice for successful outcomes. There is no need to remove the plates, which are gradually absorbed within 2 to 3 years [10]. It is important that this artificial strut be in contact with the "keystone area" and maxillary crest. The mechanical strength provided by a buttress lasts for a long time before the strut is absorbed. However, if the septal mucosa is not intact, our procedure is not indicated. Two cases were excluded from this series for this reason. It should also be noted that because the plate is expensive, each patient's economic status should be considered when surgeons plan to use our surgical method.

\section{REFERENCES}

1. Rohrich RJ, Adams WP Jr. Nasal fracture management: minimizing secondary nasal deformities. Plast Reconstr Surg 2000;106:266-73.

2. Verwoerd CD. Present day treatment of nasal fractures: closed versus open reduction. Facial Plast Surg 1992;8:220-3.

3. Renner GJ. Management of nasal fractures. Otolaryngol Clin North Am 1991;24:195-213.

4. Yabe T, Muraoka M. Treatment of saddle type nasal fracture using Kirschner wire fixation of nasal septum. Ann Plast Surg 2004;53:89-92.

5. Bilen BT, Kilinc H. Reconstruction of saddle nose deformity with three-dimensional costal cartilage graft. J Craniofac Surg 2007; 18:511-5.

6. Ducic Y, Hilger PA. A reliable absorbable intranasal bolster for proper maintenance of fractured nasal bone position. Rhinology 1999;37:88-9.

7. Chin T, Sakata Y, Amenomori S, et al. Use of a bioabasorbable bone pin fixation for nasal fractures. J Nihon Med Sch 2005;72:179-81.

8. Boenisch M, Nolst Trenite GJ. Reconstructive septal surgery. Facial Plast Surg 2006;22:249-54.

9. Watzinger F, Wutzl A, Wanschitz F, et al. Biodegradable polymer membrane used as septal splint. Int J Oral Maxillofac Surg 2008;37:473-7.

10. Lee HB, Oh JS, Kim SG, et al. Comparison of titanium and biodegradable miniplates for fixation of mandibular fractures. J Oral Maxillofac Surg 2010;68:2065-9. 